\title{
The Effect of Novel Polymorphisms in the Interleukin-6 (IL-6) Gene on IL-6 Transcription and Plasma IL-6 Levels, and an Association with Systemic-Onset Juvenile Chronic Arthritis
}

\author{
Daniel Fishman, ${ }^{\star}$ Gary Faulds, ${ }^{\ddagger}$ Rachel Jeffery, ${ }^{*}$ Vidya Mohamed-Ali, ${ }^{\S}$ John S. Yudkin, ${ }^{\S}$ Steve Humphries, ${ }^{\ddagger}$ and Patricia Woo* \\ *Paediatric Rheumatology Unit, Windeyer Institute of Medical Sciences, University College London Medical School, London W1P 6DB; \\ ${ }^{\ddagger}$ Centre for Genetics of Cardiovascular Disorders, Rayne Institute, London WC1E 6JJ; ${ }^{\S}$ Centre for Diabetes and Cardiovascular Risk, \\ Department of Medicine, Whittington Hospital, London N19 5UA, United Kingdom
}

\begin{abstract}
During active disease, patients with systemic-onset juvenile chronic arthritis (S-JCA) demonstrate a rise and fall in serum interleukin-6 (IL-6) that parallels the classic quotidian fever. To investigate the possibility that this cytokine profile results from a difference in the control of IL-6 expression, we examined the $5^{\prime}$ flanking region of the IL- 6 gene for polymorphisms. A G/C polymorphism was detected at position -174 . In a group of 383 healthy men and women from a general practice in North London, the frequency of the $\mathrm{C}$ allele was 0.403 (95\% confidence interval 0.37-0.44). In comparison, 92 patients with S-JCA had a different overall genotype frequency, especially those with onset of disease at $<5$ yr of age. This was mainly due to the statistically significant lower frequency of the CC genotype in this subgroup. When comparing constructs of the $5^{\prime}$ flanking region $(-550-+61 \mathrm{bp})$ in a luciferase reporter vector transiently transfected into HeLa cells, the $-174 \mathrm{C}$ construct showed $0.624 \pm 0.15$-fold lower expression than the $-174 \mathrm{G}$ construct. After stimulation with LPS or IL-1, expression from the $-174 \mathrm{C}$ construct did not significantly change after $24 \mathrm{~h}$, whereas expression from the $-174 \mathrm{G}$ construct increased by $2.35 \pm 0.10$ - and $3.60 \pm 0.26$-fold, respectively, compared with the unstimulated level. Plasma levels of IL-6 were also measured in 102 of the healthy subjects, and the $\mathrm{C}$ allele was found to be associated with significantly lower levels of plasma IL-6. These results suggest that there is a genetically determined difference in the degree of the IL- 6 response to stressful stimuli between individuals. The reduced frequency
\end{abstract}

The first two authors contributed equally to this study.

During the preparation of this manuscript, the $-174 \mathrm{G} / \mathrm{C}$ polymorphism was independently submitted to GenBank (GenBank accession number AF005485, authors Olomolaiye, O.O., N.A.P. Wood, and J.L. Bidwell, unpublished). We have submitted the $A_{n} T_{n}$ polymorphism and corrections to the original sequence to GenBank (accession numbers AF039224-8 inclusive).

Address correspondence to Prof. P. Woo, Paediatric Rheumatology Unit, Windeyer Institute of Medical Sciences, University College London Medical School, 46 Cleveland Street, London W1P 6DB England. Phone: +44-171-380-9148; FAX: +44-171-436-0783; E-mail: patricia.woo@ucl.ac.uk

Received for publication 22 December 1997 and accepted in revised form 11 August 1998.

J. Clin. Invest.

(C) The American Society for Clinical Investigation, Inc. 0021-9738/98/10/1369/08 \$2.00

Volume 102, Number 7, October 1998, 1369-1376

http://www.jci.org of the potentially protective CC genotype in young S-JCA patients may contribute to its pathogenesis. Similarly the individual's IL-6 genotype may be highly relevant in other conditions where IL-6 has been implicated, such as atherosclerosis. (J. Clin. Invest. 1998. 102:1369-1376.) Key words: cytokine $\cdot \mathrm{SSCP} \cdot \mathrm{JCA} \cdot$ genetics $\bullet$ transfection

\section{Introduction}

Juvenile chronic arthritis (JCA $)^{1}$ is one of the commonest forms of chronic childhood disability, with an annual UK incidence of 10 cases per 100,000 children under $16 \mathrm{yr}$ of age (1). Approximately $11 \%$ of patients with JCA suffer from the systemic-onset form (S-JCA), which is the subgroup most likely to be associated with severe, debilitating, extra-articular features and occasionally fatal complications $(1,2)$. To control their disease, young children with S-JCA are often exposed to potentially toxic therapies for many years. However, many children still experience early joint destruction, necessitating surgical replacement. Moreover, up to $48 \%$ of these patients will still have active disease after $10 \mathrm{yr}$ (3).

S-JCA is a clinically homogeneous and quite unique illness. When the disease is active, patients display a typical quotidian spiking fever, an evanescent macular rash, lymphadenopathy, hepatosplenomegaly, serositis, myalgia, and arthritis. They are frequently anemic with markedly raised neutrophil and platelet counts; they have a high erythrocyte sedimentation rate, C-reactive protein, and serum fibrinogen. Patients also have a polyclonal hypergammaglobulinaemia and in severe cases raised liver enzymes and a coagulopathy (4). Additionally, inflammatory cytokines, such as tumor necrosis factor $(\mathrm{TNF}-\alpha)$, interleukin-1 (IL-1), and interleukin-6 (IL-6) have been shown to be elevated in the serum and synovial fluid of inflamed joints (5-8).

The particularly unusual feature of acute S-JCA is the unique pattern of fever. Once, or occasionally twice a dayand sometimes at the same time each day-the patient's temperature rapidly rises, often to more than $40^{\circ} \mathrm{C}$. Patients may remain febrile for several hours before their temperature returns to normal, or subnormal. 24-h serum cytokine profiles have demonstrated that the serum IL- 6 concentration rises significantly in conjunction with the fever spike, and then falls in parallel with the return of body temperature to normal $(9,10)$. Over this period TNF $\alpha$ levels are only moderately elevated and reach their maximum level $\sim 5 \mathrm{~h}$ after the peak of fever.

1. Abbreviations used in this paper: JCA, juvenile chronic arthritis; S-JCA, systemic-onset juvenile chronic arthritis; SSCP, single-strand conformational polymorphism. 
The level of interleukin-1 receptor antagonist also parallels the fever curve but with a lag phase of $\sim 1 \mathrm{~h}$. This is consistent with the fact that IL-1 receptor antagonist expression is rapidly induced by IL- $6(11,12)$, and this probably contributes to the consistently low interleukin-1 $\beta$ (IL-1 $\beta$ ) concentrations found during the fever curve.

Many of the clinical and laboratory features of S-JCA are a reflection of a vigorous hepatic acute phase response, the chief stimulus of which is IL-6. Furthermore, the systemic features resemble those of other conditions where there is overexpression of IL-6, such as Castleman's disease (13) and multiple myeloma (14). IL-6 has been shown to mediate fever induced by IL-1 in animals (15) and to induce fever when administered to patients with malignancy (16). Although TNF- $\alpha$ and IL-1 may also have an important role in S-JCA, the temporal patterns of increase in the serum concentration of these two cytokines are unlikely to be the cause of the cyclical levels of IL- 6 or the characteristic fever of S-JCA (9). The central role of TNF- $\alpha$ in the pathogenesis of RA was demonstrated by the beneficial effect of humanized anti-TNF- $\alpha$ monoclonal antibody therapy on disease activity (17). However, the pathogenesis of S-JCA is likely to be different, since treatment with this antibody in one patient resulted in the abolition of fever for a few days, but the arthritis and malaise did not respond (18).

To explain the unique cyclical pattern of IL-6 serum concentration in active S-JCA, we have proposed that the regulation of the expression of IL-6 in these patients differs from unaffected individuals, possibly as the result of $5^{\prime}$ flanking region polymorphisms. There are now several well-documented instances where nucleotide polymorphisms occur within the regulatory region of cytokine genes, and some of these are associated with an altered rate of expression of the gene (19-21). In addition, some examples of these polymorphisms have been associated with autoimmune diseases, such as the combination of oligoarthritis with uveitis and a polymorphism of IL- $1 \alpha$ in Norwegian patients (22) (although this is not confirmed for UK oligoarthritis patients [23]) and infectious diseases (24-26).

In this paper, we report the presence of polymorphisms within the $5^{\prime}$ flanking region of the IL- 6 gene. One of these lies in an area previously reported to have a negative effect on gene transcription. We demonstrate that it affects the transcription rate of a reporter gene in transient transfection studies and is associated with lower plasma IL-6 levels in normal individuals. Furthermore, there was a significant difference in the frequency of genotypes between patients with S-JCA and the controls.

\section{Methods}

Patients and controls. Genomic DNA from Anglo-Saxon Caucasian patients with S-JCA was extracted as previously described (27) from blood samples collected at Northwick Park Hospital and from Great Ormond Street Hospital for Sick Children and University College London Hospitals. In all cases, samples were obtained from blood taken during routine clinical analysis. The ARC DNA Repository at the University of Manchester, England also kindly provided us with genomic DNA samples from other Anglo-Saxon Caucasian S-JCA patients. All patients had an age of onset of disease below $16 \mathrm{yr}$ and had a persistent polyarthritis for at least $5 \mathrm{yr} .53 \%$ of the patients were female. Genomic DNA was also collected from healthy members of staff at Northwick Park Hospital but used only for sequencing and RFLP analysis during the search for polymorphisms, and not for assessing genotype frequencies.

Caucasian control DNA was obtained from 383 healthy men and women aged 40-75 yr recruited originally from a general practice in North London as part of the Goodinge Study, which was designed to investigate associations of urinary albumin excretion rate with cardiovascular disease in nondiabetic subjects. Full details of these subjects have been described elsewhere $(28,29)$.

The characteristics of the subjects of Gujarati Indian and AfroCaribbean origin from the Brent and Harrow study have also been described previously (30). DNA was extracted by the salting-out method (31). DNA samples from three orangutans, three chimpanzees, and three gorillas (a kind gift of Dr. David Hunt, Institute of Ophthalmology, London, UK) was also used.

Polymerase chain reaction. The sequence of each PCR primer set is given in Table I. Primer set 1 amplified a region of $611 \mathrm{bp}$, starting upstream of the proximal putative glucocorticoid response element and finishing immediately adjacent to the main translation start site. The cycling conditions were: $95^{\circ} \mathrm{C}$ for $5 \mathrm{~min}$, followed by the addition of $0.5 \mathrm{U}$ of $\mathrm{Taq}$ polymerase (Promega, UK), then 25 cycles of $95^{\circ} \mathrm{C}$ for $1 \mathrm{~min}, 63^{\circ} \mathrm{C}$ for $1 \mathrm{~min}$, and $72^{\circ} \mathrm{C}$ for $2 \mathrm{~min}$, followed by a terminal 10 -min extension phase at $72^{\circ} \mathrm{C}$. Primer set 2 generated a PCR fragment encompassing the product of set 1 but extending 100 bases upstream and 148 bases downstream. Cycling conditions were similar to set 1 , except that an annealing temperature of $62^{\circ} \mathrm{C}$ was used; 35 cycles were carried out.

PCR for single-strand conformational polymorphism (SSCP) and MADGE system RFLP (protocols developed by G. Faulds and S.

Table I. Sequences of Primers Used to Generate PCR Products for the Analysis of the IL-6 5' Flanking Region

\begin{tabular}{ll}
\hline Name of primers & \multicolumn{1}{c}{ Nucleotide sequence of primers } \\
\hline Set 1 & $5^{\prime}$-CAG AAG AAC TCA GAT GAC TGG-3' (5/2) \\
Set 2 & $5^{\prime}$-GCT GGG CTC CTG GAG GGG-3' (3/2) \\
Set 3 & $5^{\prime}$-GGA GTC ACA CAC TCC ACC T-3' (DF20) \\
& $5^{\prime}$-GTG ACT GAC AGC ACA GCT-3' (DF21) \\
Set 4 & $5^{\prime}$-TGA CTT CAG CTT TAC TCT TGT-3' \\
& $5^{\prime}$-CTG ATT GGA AAC CTT ATT AAG-3' \\
DF13 & $5^{\prime}$-CTG GTA GTA TTA CCT TCT TCA-3' \\
DF14 & $5^{\prime}$-TTC TTT ATT AGT GAC TCA GCA-3' \\
DF5/2D & $5^{\prime}$-CCT TCT TCA TAA TCC AGG-3' \\
DF3/2D & $5^{\prime}$-GAG CTT CTC TTT GCT TCC-3' \\
& $5^{\prime}$-TAT GCG AGG TAC CAG AAG AAC TCA GAT GAC TGG-3' \\
& $5^{\prime}$-AGT TAA TCT AGA TAT GCT GGG CTC CTG GAG GGG-3'
\end{tabular}

Upstream primer of each pair is described first. 
Humphries) were carried out using primer sets 3 and 4 . The cycling conditions were: five cycles: of $96^{\circ} \mathrm{C}$ for $9 \mathrm{~min}, 95^{\circ} \mathrm{C}$ for $1 \mathrm{~min}$, and $72^{\circ} \mathrm{C}$ for $3 \mathrm{~min}$, followed by 30 cycles of: $95^{\circ} \mathrm{C}$ for $1 \mathrm{~min}, 55^{\circ} \mathrm{C}$ for $1 \mathrm{~min}$, and $72^{\circ} \mathrm{C}$ for $1 \mathrm{~min}$. Primer sets 3 and 4 were part of a group of six primer pairs (others not shown) used by two of us (G. Faulds and S. Humphries) to screen 1179 bp of the $5^{\prime}$ flanking region by SSCP. Only products from these two primer pairs displayed SSCP changes in this study and were further investigated by automated sequencing.

SSCP. SSCP was carried out according to the method of Orita et al. (32) with some modifications. ${ }^{33} \mathrm{P}-\mathrm{dATP}$-labeled primer set 1 product was digested with Mae III. $9 \mu$ l of digested PCR product was diluted with SSCP running buffer $(10 \mathrm{nM} \mathrm{NaOH}, 80 \%$ formamide, $1 \mathrm{mM}$ EDTA, and $0.1 \%$ each BPB and XC). The sample was heated to $95^{\circ} \mathrm{C}$ for $5 \mathrm{~min}$ and then placed on ice. $10 \mu \mathrm{l}$ of each sample was run at $5 \mathrm{~W}$ overnight $(18 \mathrm{~h})$ on a $6 \%$ nondenaturing polyacrylamide gel (MDE; Anachem, Luton, UK) at room temperature. Alternatively, 2 $\mu l$ of PCR product generated by primer sets 3 or 4 was added to $6 \mu l$ of a 7:5 ratio of formamide dye mix (95\% formamide, $10 \mathrm{mM}$ EDTA, and $0.02 \% \mathrm{wt} / \mathrm{vol}$ each of BPB and XC) and a solution of $0.1 \% \mathrm{wt} / \mathrm{vol}$ SDS and $10 \mathrm{mM}$ EDTA. The DNA was denatured at $95^{\circ} \mathrm{C}$ for $5 \mathrm{~min}$, and then placed on ice. $4 \mu \mathrm{l}$ of each sample was run overnight at $300 \mathrm{~V}$ on a $7.5 \%$ nondenaturing polyacrylamide gel with $5 \% \mathrm{vol} / \mathrm{vol}$ glycerol and $10 \mathrm{mM}$ EDTA at room temperature (33).

Sequencing of the IL-6 5' flanking region. Initially, $1 \mu \mathrm{l}$ of PCR product generated from genomic DNA from S-JCA patients and staff controls by using primer pair 1 was ligated into the pCRII vector (Invitrogen, Groningen, Netherlands). This was then used to transform competent Escherichia coli (Invitrogen). Plasmid DNA prepared by the Wizard Miniprep kit (Promega, Southampton, UK) was sequenced with Vent polymerase (ThermoCycle Kit; NEB, Hitchin, UK) by using the primers shown in Table II. Subsequently, the same PCR product was sequenced using the Vistra 725 automated sequencing system (Amersham, Little Chalfont, UK). 5'-Texas Redlabeled sequencing primers (DF13 and DF14; Oswell, Southampton, UK) were nested within the location of the original PCR primers. The reaction parameters were: $95^{\circ} \mathrm{C}$ for $3 \mathrm{~min}$, followed by 25 cycles of $95^{\circ} \mathrm{C}$ for $30 \mathrm{sec}, 51^{\circ} \mathrm{C}(\mathrm{DF} 13)$ or $50^{\circ} \mathrm{C}$ (DF14) for $15 \mathrm{sec}$, and $72^{\circ} \mathrm{C}$ for $30 \mathrm{sec}$.

PCR products from Caucasian, Gujarati, and Afro-Caribbean control DNA samples generated using primer sets 3 and 4 were sequenced using the ABI Prism 377 system, using 3.2 pmol of the 5' primer from the initial PCR and $0.1 \mathrm{pmol} / \mu \mathrm{lCR}$ product. Cycle sequencing was: $96^{\circ} \mathrm{C}$ for $30 \mathrm{sec}, 50^{\circ} \mathrm{C}$ for $15 \mathrm{sec}$, and $60^{\circ} \mathrm{C}$ for $4 \mathrm{~min}$, for 25 cycles.

Restriction fragment length polymorphisms. $10 \mu \mathrm{l}$ of PCR product generated from S-JCA patient genomic DNA by using primer sets 1 or 2 was digested with Sfa NI. After digestion the sample was denatured at $65^{\circ} \mathrm{C}$ for $5 \mathrm{~min}$, then placed on ice for $5 \mathrm{~min}$ before electrophoresis on a $1 \%$ agarose gel. PCR reactions and restriction digests

Table II. Sequence of Primers Used for Manual Sequencing

\begin{tabular}{ll}
\hline \multicolumn{1}{c}{ Nucleotide sequence of primers } & \multicolumn{1}{c}{ Name of primers } \\
\hline 5'-CAG AAG AAC TCA GAT GAC TGG-3' & $5 / 2$ \\
5'-GCT GGG CTC CTG GAG GGG-3' & $3 / 2$ \\
$5^{\prime}$-TTC ACA CAG GAA ACA G-3' & M13 reverse, within \\
& pCRII vector \\
5'-GTC AGA GGA AAC TCA GTT CAG-3' & DF3 \\
5'-GTG CAT GAC TTC AGC TTT AC-3' & DF4 \\
5'-GTG GTT CTG CTT CTT AGC-3' & DF5 \\
5'-GGA CGT CAC ATT GCA C-3' & DF6 \\
5'-GAG TCT CAA TAT TAG AGT CT-3' & DF7 \\
5'-GTC GTG ACT GGG AAA AC-3' & M13 forward, within \\
& pCRII vector
\end{tabular}

were carried out in duplicate. $12 \mu \mathrm{l}$ of primer set 3 PCR product, generated from the Caucasian, Gujarati Indian, and Afro-Caribbean control sample genomic DNA, was digested with either Hsp 92II or Nla III. Analysis of the fragments was undertaken using the 96-well MADGE system (34). Restriction enzymes were obtained from Promega and New England Biolabs, Hitchin, UK.

Reporter gene constructs. PCR primers annealing to the same sequences as primer set 1 but containing recognition sites for Kpn I in the upstream primer (DF5/2D) and Xba I in the downstream primer (DF3/2D) were used to produce a 614-bp product $(-550-+61 \mathrm{bp})$ from $\mathrm{pCR}$ II clones containing either a $\mathrm{G}$ or a $\mathrm{C}$ at the -174 position. For consistency, both clones contained the $\mathrm{A}_{8} \mathrm{~T}_{12}$ allele, allowing a direct comparison between the $\mathrm{G}$ and $\mathrm{C}$ alleles to be made without the confounding effects of a different $A_{n} T_{n}$ allele between the two reporter constructs. This allele was chosen because it represented the commonest observed allele associated with the $-174 \mathrm{C}$ allele. PCR conditions were the same as for primer set 2, with the exception that the primer annealing temperature was $67^{\circ} \mathrm{C}$ and 25 cycles were carried out. After restriction enzyme digestion, the products were directionally ligated into the pGL3 Basic Luciferase vector (Promega), linearized by digestion with Kpn I and Nhe I. Transfection-grade plasmid was prepared using the standard alkaline lysis "maxiprep" procedure, followed by two caesium chloride centrifugation gradients. Alternatively, plasmids were prepared using the Qiagen Midiprep system (Qiagen, UK). Before transfection, the sequence of each cloned product was confirmed by automated sequencing.

Transient transfections. $4 \times 10^{5} \mathrm{HeLa}$ cells (ATCC, Rockville, $\mathrm{MD})$ were seeded into each well of a six-well plate and grown to confluence (2 d) in Dulbecco's modified Eagle's medium (GIBCO BRL, Paisley, UK), supplemented with $10 \%$ heat-inactivated fetal calf serum, nonessential amino acids, and penicillin $(50 \mathrm{U} / \mathrm{ml}) /$ streptomycin $(50 \mu \mathrm{g} / \mathrm{ml})$, all obtained from Sigma (Poole, UK). The HeLa cells were transfected with $10 \mu \mathrm{g}$ of each reporter plasmid and $3 \mu \mathrm{g}$ of a control plasmid containing the $\beta$-galactosidase gene (RSV- $\beta$-gal), which lacks a cytokine responsive promoter, by the calcium phosphate method (35). After $18 \mathrm{~h}$, the cells were stimulated with either IL-1 $(10 \mathrm{U} / \mathrm{ml})$ or LPS $(10 \mu \mathrm{g} / \mathrm{ml})$. After a further $24 \mathrm{~h}$, the cells were harvested. Luciferase and $\beta$-galactosidase expression were measured using commercial assay kits (Luciferase Assay; Promega and GalactoLight Plus; Tropix, Bedford, MA) in a BioOrbit 1253 luminometer (Labtech, Uckfield, UK). Each transfection was carried in duplicate, and transfections were done twice each.

Measurement of plasma IL-6. Plasma IL-6 levels were measured from blood samples obtained in the early morning, after an overnight fast. All the subjects were healthy at the time of venesection. The samples were analyzed in duplicate using a commercially available ELISA kit (R \& D Systems, Oxon, UK) as described previously (36).

Statistical methods. The gene-counting method with a $\chi^{2}$ test with Yates correction was used to compare the frequency of the $\mathrm{C}$ allele between the different groups. All other tests and transformations were performed using the SPSS/PC + statistical package. The $t$ test was used to compare levels of luciferase between constructs. Statistical significance was considered to be at the 0.05 level. ANOVA was used to compare concentrations of plasma IL- 6 between individuals with different IL- 6 genotypes. To test differences in IL- 6 concentrations, values were log-transformed before statistical analysis. Multiple linear regression was used to adjust for the effects of age, body mass index, gender, and smoking on plasma levels of IL-6 and the adjusted values used in the ANOVA. Original rather than log transformed values are presented for clarity.

\section{Results}

SSCP analysis. The region of the IL-6 gene investigated is shown in Fig. 1. Significant interindividual differences in SSCP banding patterns were observed for Mae III digested primer set 1 PCR products and for the nondigested primer set 3 and 4 products. 


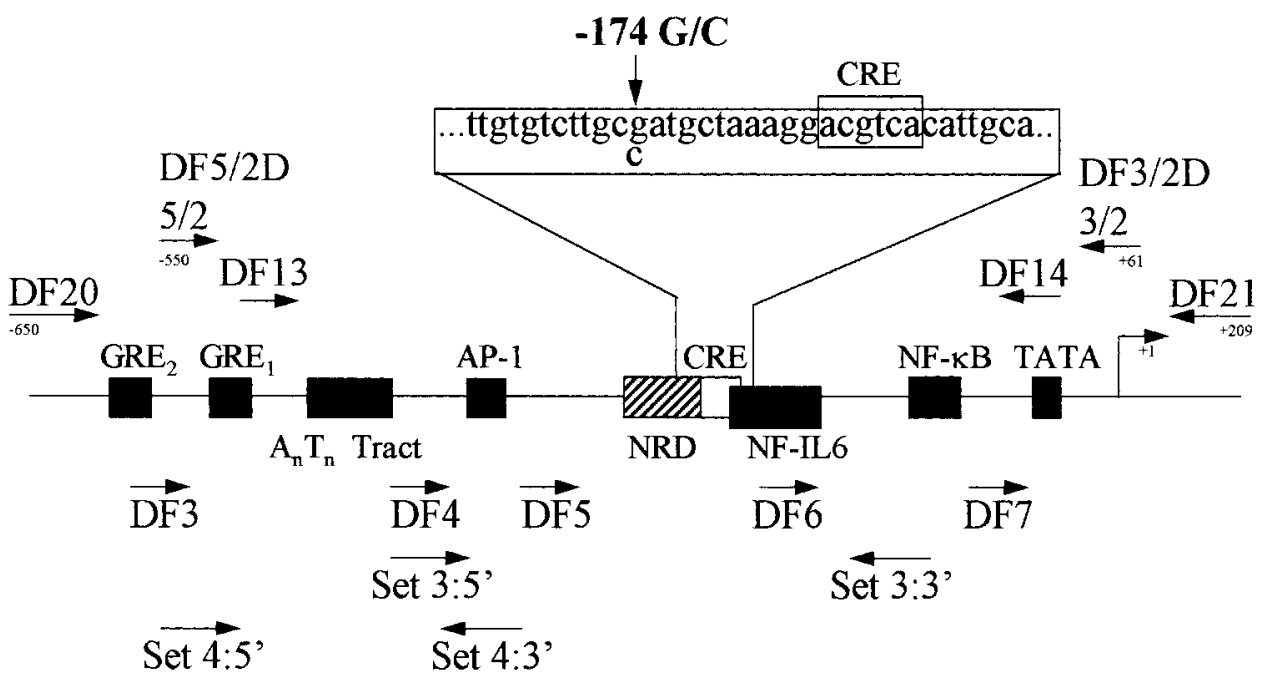

Figure 1. A schematic representation of the $5^{\prime}$ flanking region of the IL-6 gene identifying the $174 \mathrm{G} / \mathrm{C}$ polymorphism, transcription factor binding sites, and the position and orientation of the oligonucleotide pairs used in the SSCP, RFLP, and sequencing analysis. Locations of the binding sites are relative to the major transcription start site: TATA box -27 to -24 ; NF- $\mathrm{BB}-73$ to -64 ; NF-IL-6 (C/EBP $\beta)-158$ to -145 ; CRE (cAMP responsive element) -163 to -158 ; NRD (negative regulatory domain) -225 to -164 ; AP-1 -283 to $-277 ; \mathrm{A}_{\mathrm{n}} \mathrm{T}_{\mathrm{n}}$ tract -392 to $-373 ; \mathrm{GRE}_{1}$ and $\mathrm{GRE}_{2}$ (glucocorticoid responsive elements 1 and 2) -466 to -461 and -557 to -552 , respectively.
Overall, these features were highly suggestive for the presence of variations in the nucleotide sequence in these regions.

$G$ to $C$ polymorphism at position -174 . Initially the 611-bp primer set 1 PCR product from 41 staff controls and 19 patients with S-JCA was cloned into the pCRII vector and sequenced by a combination of manual and automated sequencing. Compared with the published sequence of Yasukawa et al. (37), a $\mathrm{G}$ to $\mathrm{C}$ polymorphism was identified at position -174 in 14 of these controls and 7 of the S-JCA cases $(35 \%$ of the total samples). It was independently confirmed (by G. Faulds and S. Humphries) by automated sequencing of 12 examples of the primer set 3 PCR product, 6 with each SSCP appearance, corresponding to either allele. The polymorphism produced an RFLP that was identified by three restriction enzymes, Sfa NI, Hsp 92II, and Nla III. The sensitivity and specificity of each RFLP method was demonstrated as each was able to correctly recognize the genotype identified by sequencing (data not shown).

The $\mathrm{C}$ allele and genotype frequencies of the 383 Caucasian controls, 115 Gujarati Indians, and 101 Afro-Caribbeans analyzed by MADGE system RFLP are shown in Table III. The frequency of the $\mathrm{C}$ allele in the different racial groups was 0.403 (0.37-0.44), $0.150(0.094-0.184)$, and 0.05 (0.016-0.072), respectively.

Table III. Results of MADGE PCR-RFLP for the -174 Polymorphism, Showing the Genotype Distribution and $C$ Allele Frequency (95\% confidence interval) in Subjects of Different Ethnic Origin

\begin{tabular}{lccc}
\hline \multicolumn{1}{c}{ Genotype } & $\begin{array}{c}\text { UK Caucasian male } \\
\text { and female controls } \\
(n=383)\end{array}$ & $\begin{array}{c}\text { Gujarati } \\
\text { Indians } \\
(n=115)\end{array}$ & $\begin{array}{c}\text { Afro- } \\
\text { Caribbeans } \\
(n=101)\end{array}$ \\
\hline GG & 144 & 85 & 92 \\
GC & 169 & 28 & 9 \\
CC & 70 & 2 & 0 \\
C allele & 0.403 & 0.150 & 0.05 \\
Frequency (95\% CI) & $(0.37-0.44)$ & $(0.094-0.184)$ & $(0.016-0.072)$
\end{tabular}

All three racial groups were in Hardy-Weinberg equilibrium. $\chi^{2}$ values were: Caucasians $2.7(P=0.10)$, Gujaratis $0.03(P=0.86)$, and AfroCaribbeans $0.22(P=0.64)$.
The distribution of the age of onset of S-JCA in our sample is shown in Fig. 2. The peak age of onset of disease in this group was at 2 yr. Table IV shows the genotype and $\mathrm{C}$ allele frequencies for the S-JCA patients (both as a whole and divided into onset at or before $5 \mathrm{yr}$ and onset at or after $6 \mathrm{yr}$ of age), compared with Caucasian controls. There was no significant difference between the $\mathrm{C}$ allele frequencies in the controls and any of the S-JCA patient groups. However, the overall genotype distribution of the whole patient group was significantly different than the controls $\left(P=0.03, \chi^{2}=6.82\right)$. In the $\leq 5$-yr-old onset group, this difference was even greater $(P=$ $\left.0.01, \chi^{2}=8.94\right)$. When the genotype frequencies of the S-JCA patients and the controls were compared, there was a statistically significant reduction in CC genotype frequency in the S-JCA patients with age of onset $\leq 5 \mathrm{yr}\left(P=0.04, \chi^{2}=4.32\right.$, OR $0.34,95 \%$ CI $0.12-0.98$ ).

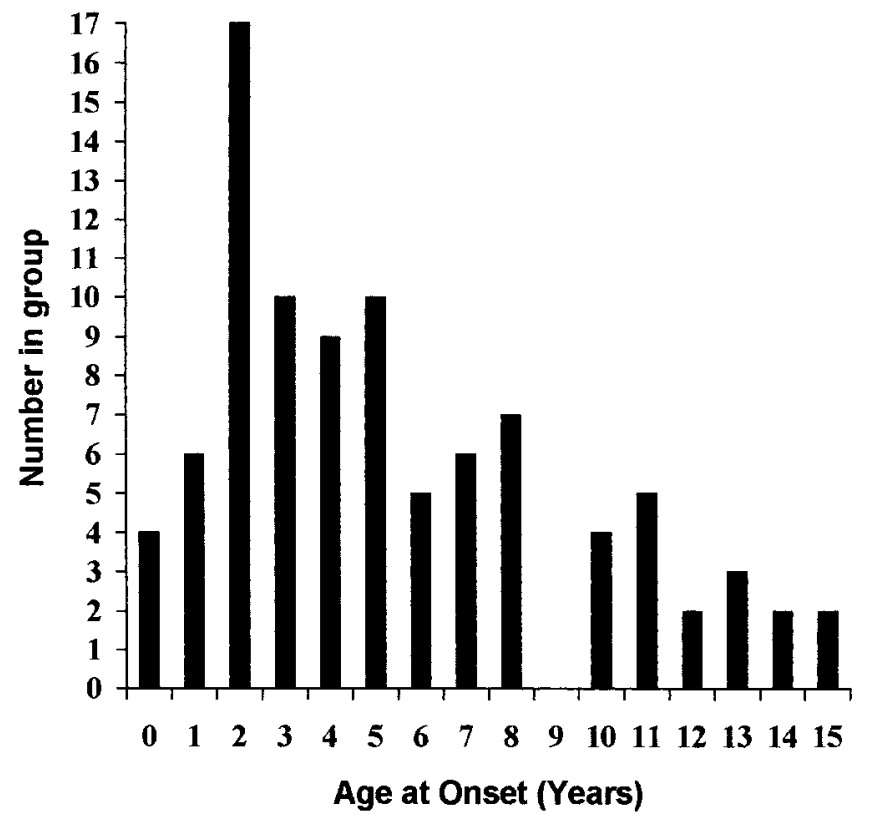

Figure 2. Age of onset distribution for patients with S-JCA. The peak age of onset in the group studied here was $2 \mathrm{yr}$. $61 \%$ of the patients had an age of onset of $5 \mathrm{yr}$ or below. 
Table IV. Results of the RFLP Analysis of Patients with S-JCA, Showing the Genotype and C Allele Frequencies, Compared with the UK Control Caucasian Group

\begin{tabular}{|c|c|c|c|c|}
\hline Genotype & $\begin{array}{l}\text { All S-JCA patients } \\
\qquad(n=92)\end{array}$ & $\begin{array}{c}\text { S-JCA Onset } \leq 5 \text { yr old } \\
(n=56)\end{array}$ & $\begin{array}{c}\text { S-JCA Onset } \geq 6 \text { yr old } \\
(n=36)\end{array}$ & $\begin{array}{l}\text { UK Caucasian male } \\
\text { and female controls } \\
\qquad(n=383)\end{array}$ \\
\hline GG & $28(0.30)$ & $16(0.29)$ & $12(0.33)$ & $144(0.38)$ \\
\hline GC & $54(0.59)$ & $36(0.64)$ & $18(0.50)$ & $169(0.44)$ \\
\hline $\mathrm{CC}$ & $10(0.11)$ & $4(0.07)$ & $6(0.17)$ & $70(0.18)$ \\
\hline C-allele & 0.402 & 0.393 & 0.417 & 0.403 \\
\hline Frequency* & $(0.33-0.47)$ & $(0.30-0.48)$ & $(0.30-0.53)$ & $(0.37-0.44)$ \\
\hline \multirow[t]{2}{*}{ Patients** vs. controls } & $P=0.03$ & $P=0.01$ & $P=0.79$ & \\
\hline & $\chi^{2}=6.82$ & $\chi^{2}=8.94$ & $\chi^{2}=0.46$ & \\
\hline
\end{tabular}

$* 95 \%$ CI. ** Overall genotype distribution analyzed by $\chi^{2}$ test.

Other polymorphisms. We also observed a variation in the composition of the $A_{n} T_{n}$ tract at the published positions -392 to -373 , the published nucleotide sequence being $A_{9} T_{11}$ (37). We assessed the composition of the $A_{n} T_{n}$ tract in a total of 57 subjects (32 staff controls and 25 S-JCA patients) by sequencing of cloned PCR products. Three patterns of 20 base length were observed: $\mathrm{A}_{8} \mathrm{~T}_{12}(n=24), \mathrm{A}_{9} \mathrm{~T}_{11}(n=12)$, and $\mathrm{A}_{10} \mathrm{~T}_{10}(n=$ 10). Two patterns of 19 bases: $\mathrm{A}_{9} \mathrm{~T}_{10}(n=3)$ and $\mathrm{A}_{10} \mathrm{~T}_{9}(n=1)$ and one pattern of 21 bases: $\mathrm{A}_{10} \mathrm{~T}_{11}(n=7)$ were also seen. In all but one case, the $-174 \mathrm{C}$ allele was associated with the $\mathrm{A}_{8} \mathrm{~T}_{12}$ pattern (Table $\mathrm{V}$ ).
In addition, we consistently observed that the published sequence had underestimated two triplets of $\mathrm{C}$ residues, at positions -508 and +15 , as pairs of $\mathrm{C}$ residues. This is likely to represent a technical error in the reported sequence.

Functional studies. Fig. 3 shows the results of transient transfection experiments in HeLa cells by using constructs containing either allele of the $-1745^{\prime}$ flanking region polymorphism. Correction for variations in transfection efficiency and cell lysate recovery was achieved by dividing the luciferase luminescence value by that for $\beta$-galactosidase control (38). The results of two separate experiments (each performed in

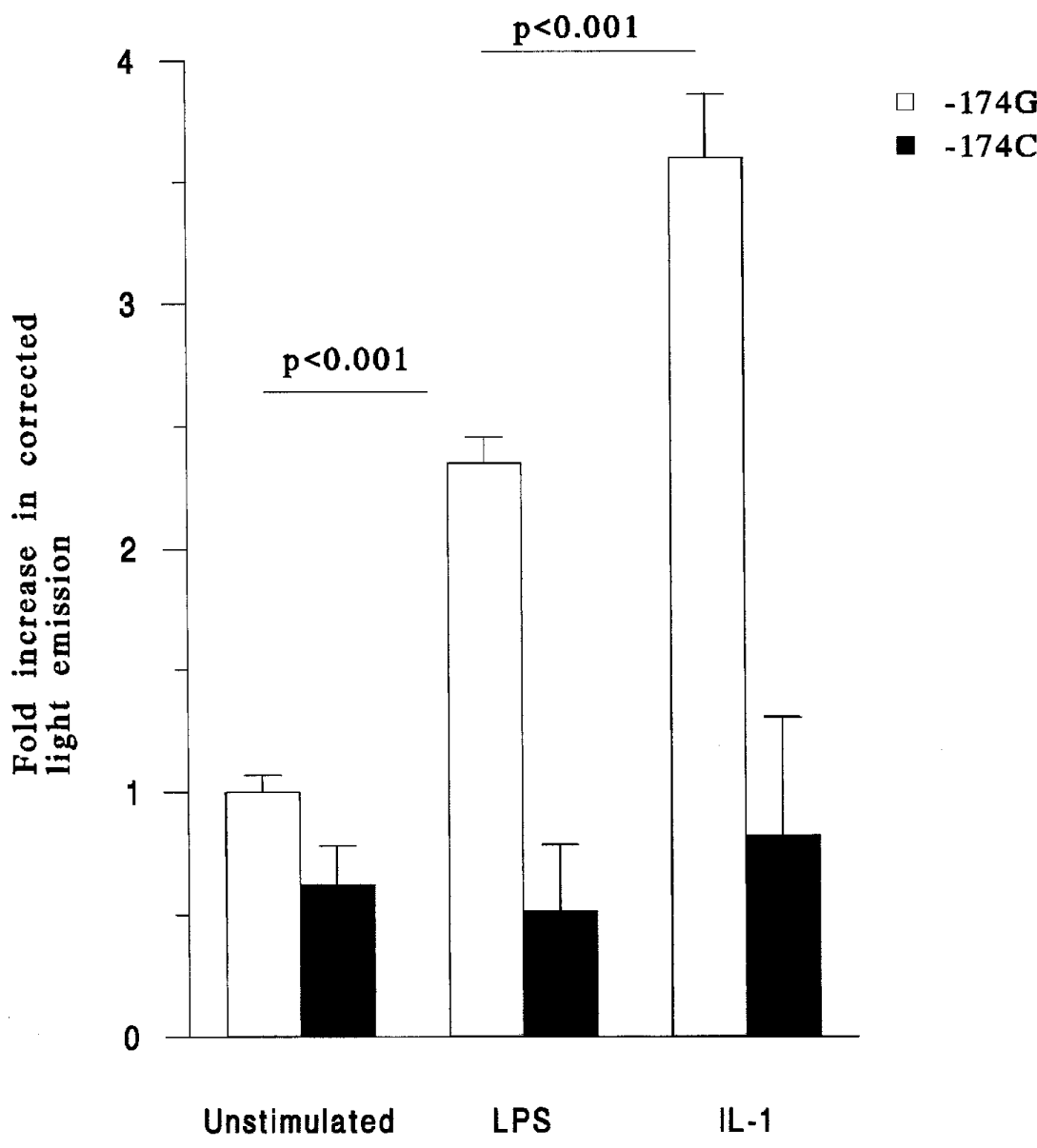

Figure 3. Luciferase activity (SD), measured as the fold increase in light emission relative to the unstimulated $\mathrm{G}\left(\mathrm{A}_{8} \mathrm{~T}_{12}\right)$ construct, of $\mathrm{G}\left(\mathrm{A}_{8} \mathrm{~T}_{12}\right)$ and $\mathrm{C}\left(\mathrm{A}_{8} \mathrm{~T}_{12}\right)$ constructs expressed in HeLa cells. Results are the mean of four transfections, corrected for protein content and efficiency of transfection by $\beta$-galactosidase cotransfection. 
duplicate), where the plasmids were prepared by caesium chloride gradient separation or Qiagen preparation, were combined by calculating the fold change in corrected luciferase expression relative to the unstimulated $-174 \mathrm{G}$ allele. In unstimulated cells, the $\mathrm{C}\left(\mathrm{A}_{8} \mathrm{~T}_{12}\right)$ construct showed $0.62 \pm 0.15$-fold lower $(P<0.005)$ expression than the $\mathrm{G}\left(\mathrm{A}_{8} \mathrm{~T}_{12}\right)$ construct. After stimulation with lipopolysaccharide or IL-1, expression from the $\mathrm{G}\left(\mathrm{A}_{8} \mathrm{~T}_{12}\right)$ construct increased by $2.35 \pm 0.10$-fold and $3.60 \pm 0.26$-fold, respectively, compared with the unstimulated level (both $P<0.001$ ). However, expression from the $\mathrm{C}\left(\mathrm{A}_{8} \mathrm{~T}_{12}\right)$ construct did not change significantly $(P=0.5$ and 0.46 , respectively). LPS- and IL-1-induced luciferase expression from the $G\left(A_{8} T_{12}\right)$ construct was, respectively, 4.55 \pm 0.39 fold and 4.38 \pm 0.54 -fold that induced from the $\mathrm{C}\left(\mathrm{A}_{8} \mathrm{~T}_{12}\right)$ construct (both $P<0.0001$ ).

Plasma IL-6 levels. From the 383 healthy Caucasians, a subset of 102 subjects were recalled for measurement of their fasting plasma IL-6. In this subset, the GG homozygotes had circulating IL-6 concentrations approximately twice as high as those homozygous for the $\mathrm{C}$ allele $(P=0.02)$ (Fig. 4).

\section{Discussion}

There are now several examples of polymorphisms occurring within cytokine genes, some of which are associated with disease. A polymorphism in the promoter region of the IL- $1 \alpha$ gene has been found to be associated with pauci-articular JCA in a cohort of Norwegian children, especially in those with chronic iridocyclitis (22), but not in UK children (23). There is a strong association between a worse outcome from malaria or mucocutaneous leishmaniasis and the rare allele of the -308

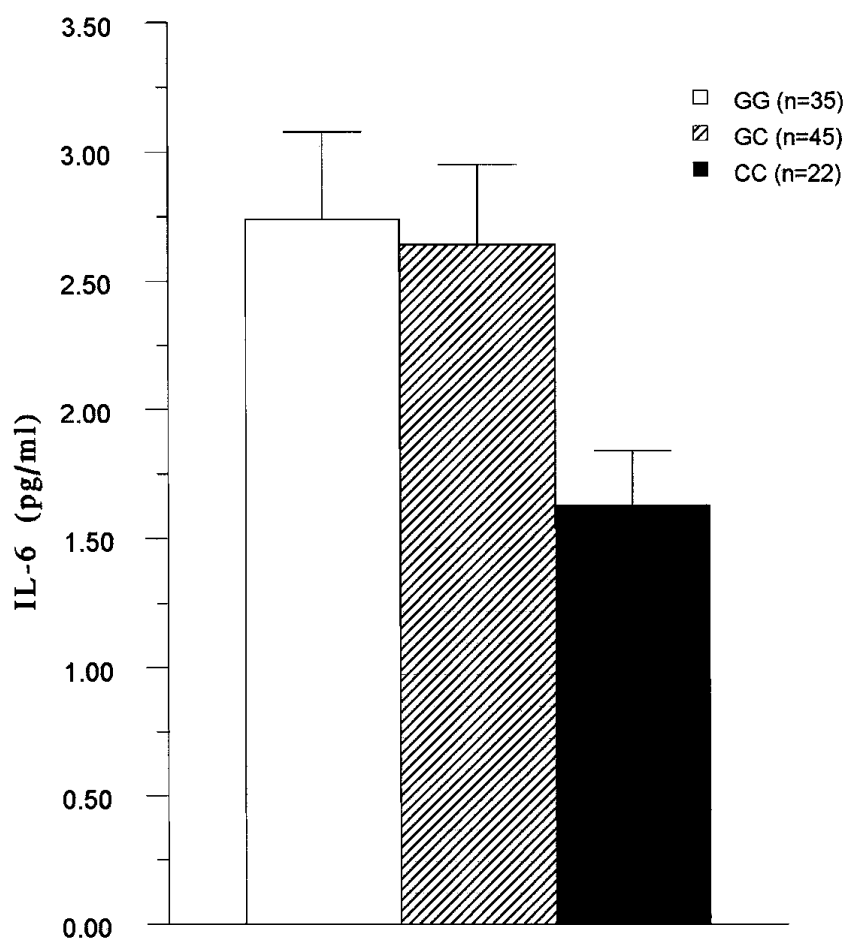

Figure 4. Mean plasma IL-6 levels in healthy men and women with different IL-6 G/C genotypes. Mean values (adjusted for age, body mass index, gender, and smoking) were GG: 2.74 (95\% CI 2.43-3.10); GC: 2.64 (2.35-2.97); CC: 1.63 (1.44-1.86). $(P=0.02$ by ANOVA).
Table V. Combined Results for Sequencing $A_{n} T_{n}$ Tract from Patient and NPH Controls

\begin{tabular}{lrrcccc}
\hline & $\mathrm{A}_{8} \mathrm{~T}_{12}$ & $\mathrm{~A}_{9} \mathrm{~T}_{11}$ & $\mathrm{~A}_{10} \mathrm{~T}_{10}$ & $\mathrm{~A}_{9} \mathrm{~T}_{10}$ & $\mathrm{~A}_{10} \mathrm{~T}_{11}$ & $\mathrm{~A}_{10} \mathrm{~T}_{9}$ \\
\hline$-174 \mathrm{G}$ & 5 & 12 & 9 & 3 & 7 & 1 \\
$-174 \mathrm{C}$ & 19 & 0 & 1 & 0 & 0 & 0
\end{tabular}

In all but one case, the $-174 \mathrm{C}$ allele was associated with the $\mathrm{A}_{8} \mathrm{~T}_{12}$ tract configuration. Considerably more variation was observed for the $A_{n} T_{n}$ tract association with the $-174 \mathrm{G}$ allele.

TNF- $\alpha$ promoter polymorphism (TNFA2) $(24,25)$. This allele has been shown to be a stronger inducer of reporter gene expression than the common allele (19). IL-6 polymorphisms have previously been reported: Msp I and Bgl I identify probable base substitutions around the fifth exon and in the $5^{\prime}$ flanking region, respectively (39). In addition, Bst NI and at least nine other enzymes identify an RFLP in an AT-rich area of the 3' flanking region, representing insertions of varying sizes. A PCR method to screen this region has been developed (40). Considerable interethnic variation in the frequencies of these polymorphisms has been demonstrated (39), which is consistent with our data for the $-174 \mathrm{C}$ allele, which is considerably rarer in Gujarati Indians and Afro-Caribbeans, compared with UK Caucasians. As all of the primates examined were GG homozygotes, it is likely that this allele is ancestral and that the $\mathrm{C}$ allele represents a relatively recent change in the IL-6 5' flanking sequence.

Until now, there have been no disease associations with any polymorphisms in the $5^{\prime}$ flanking region of the IL-6 gene. The Msp I and Bgl I RFLP are not associated with RA, SLE, or pauci-articular JCA (41). An increased frequency of an Xba I RFLP, also likely to be due to $3^{\prime}$ flanking region insertions, has been described in some patients with SLE and elevated IL-6 levels (42). By using PCR-RFLP and sensitive polyacrylamide gel electrophoresis, an association between genotype for the $3^{\prime}$ flanking region polymorphism and peak bone mineral density in women has been demonstrated (43). However, none of these RFLP are located in areas known to be responsible for inducible transcriptional control. This current report is the first description of a polymorphism in the $5^{\prime}$ flanking region that alters the transcriptional response to stimuli such as LPS and IL-1, results that have since been repeated consistently in both our laboratories.

The region between -225 to -164 containing the $\mathrm{G}$ to $\mathrm{C}$ polymorphism has previously been reported to demonstrate a negative regulatory effect on reporter gene expression (44). Studies on the repression of the IL-6 promoter by using DNA footprinting have demonstrated binding of the glucocorticoid receptor to a region around -201 . The polymorphism at -174 is close enough to this site for it to potentially influence the binding of the glucocorticoid receptor and thus its ability to repress transcriptional activation. It is of considerable interest that the change from a $\mathrm{G}$ to a $\mathrm{C}$ at position -174 creates a potential binding site for the transcription factor NF-1. NF-1 comprises a family of structurally related transcription factors active in many cell types (45). Although this factor has been shown to have varying effects on transcription, in HeLa cells it has been demonstrated to be a repressor of gene expression (46). Our work has shown that reporter gene expression from the $\mathrm{C}$ allele is repressed in HeLa cells. It is possible that in 
other cell lines this response is very different. Thus, the in vivo situation is likely to be complex, where IL-6 is expressed from several different tissues. We are currently investigating the possibility that this effect is due to binding of DNA in this region by a nuclear protein acting as a repressor in HeLa cells, by using electromobility shift assays and DNA footprinting. We are also investigating whether this reduced expression occurs in other tissue cell lines, by transient transfection experiments and if different $A_{n} T_{n}$ patterns influence this differential expression.

The genotype frequencies in our S-JCA patient group is significantly different from that in a large control population. The reduction in the prevalence of the $\mathrm{CC}$ genotype in patients with S-JCA, especially those with disease onset at or before $5 \mathrm{yr}$, is a very interesting finding. This is the first time that a significant genetic association has been demonstrated for S-JCA. The in vitro data showing that reporter expression from the $\mathrm{C}$ allele is repressed after stimulation with IL-1 and LPS, whereas the $G$ allele induces reporter expression as would be predicted, suggest that the presence of the $\mathrm{C}$ alleleand more so the CC genotype-would result in a lower IL-6 expression after a given inflammatory stimulus compared with the GG genotype. This is supported by our in vivo observation that IL-6 levels are lower in normal subjects with the CC genotype, compared with GC or GG subjects.

The reduction in the frequency of the CC genotype in S-JCA patients therefore suggests that this genotype confers a protective influence against the development of the disease. This implies that an individual's genotype influences his or her IL-6 response to a stressful stimulus in a manner analogous to that of the TNF- $\alpha-308$ polymorphism (19). It is highly unlikely that the -174 polymorphism alone represents the susceptibility gene for the development of S-JCA. Rather, the GG (or GC) genotypes may be interacting with other genetic and/ or environmental triggers to produce the disease. Linkage between the polymorphism and S-JCA is amenable to analysis by the transmission disequilibrium test, for which we are currently collecting simplex families.

Although there is no validated method for assessing disease severity in S-JCA, the disease course of persistent arthritis in all of these patients demonstrates that they are of the moderate to severe spectrum. There is no published data concerning the incidence of S-JCA in non-Caucasians, and given the low frequency of the $\mathrm{C}$ allele in Gujarati Indians and AfroCaribbeans, it would be very interesting to investigate the genotypes of S-JCA patients in these groups. The reduction in CC genotype frequency in the $\leq 5$-yr-old onset group is very interesting. These children are frequently very unwell, with chronic disease that is difficult to suppress. The subdivision into onset before or after $5 \mathrm{yr}$ of age is also of relevance in other JCA subgroups. In particular, the young onset oligoarticular JCA subgroup is often defined by onset age 5 or below, and they have strong HLA associations that are not seen in older oligoarticular onset children (47).

Although it would be of interest to determine the association between a patient's -174 genotype and their serum IL-6 levels during active disease, and also to compare the level of IL-6 in the prefever, febrile, and postfever state between patients with different genotypes, these findings are likely to be very difficult to interpret for several reasons. First, IL-6 levels may be influenced by medication. Second, we have shown a large variation in the absolute IL- 6 level between children acutely ill with S-JCA (9). Third, other factors, such as the "severity" of disease (for which there is no agreed, objective scale), age, disease duration as well as the duration of current flare, and nutritional state are also likely to influence the serum IL-6 levels. However, the association between the $\mathrm{C}$ allele and lower levels of IL-6 in healthy fasting men and women strongly supports the in vitro finding of reduced promoter strength. We are also in the process of measuring IL-6 production by PBMC from healthy donors with different genotypes to assess the in vitro IL-6 response to inflammatory stimuli.

In summary, we have demonstrated novel polymorphisms in the $5^{\prime}$ flanking region of the IL-6 gene, an area important in the regulation of gene expression. A single nucleotide change from $\mathrm{G}$ to $\mathrm{C}$ at position -174 results in suppression of IL-6 transcription in response to LPS or IL-1 in HeLa cells. Furthermore, the $\mathrm{CC}$ genotype is significantly less common in S-JCA than in Caucasian control subjects and may play a protective role against the development of the disease.

\section{Acknowledgments}

We are grateful for the assistance of Dr. E. Crawley, Dr. B. Ansell, and the ARC DNA repository at the University of Manchester, UK, who provided additional S-JCA genomic DNA.

This work was supported by grants from the Arthritis and Rheumatism Council (Clinical Research Fellowship F0508 to D. Fishman), the Medical Research Council and the British Heart Foundation (PG/007).

\section{References}

1. Symmons, D., M. Jones, J. Osborne, J. Sills, T. Southwood, and P. Woo. 1996. Pediatric rheumatology in the United Kingdom: data from the British Pediatric Rheumatology Group National Diagnostic Register. J. Rheum. 11:13-16.

2. Laxer, R., and R. Schneider. 1993. Systemic-onset juvenile chronic (rheumatoid) arthritis and adult-onset Still's disease. In Oxford Textbook of Rheumatology. P. Maddison, D. Isenberg, P. Woo, and D. Glass, editors. Oxford Medical Publications, Oxford. 722-731.

3. Wallace, C.A., and J.E. Levinson. 1991. Juvenile rheumatoid arthritis: outcome and treatment for the 1990s. Rheum. Dis. Clin. North Am. 17:891-905.

4. Fishman, D., M. Rooney, and P. Woo. 1995. Successful management of reactive haemophagocytic syndrome in systemic-onset juvenile chronic arthritis [letter]. Br. J. Rheumatol. 34:888.

5. De Benedetti, F., M. Massa, P. Robbioni, A. Ravelli, G.R. Burgio, and A. Martini. 1991. Correlation of serum interleukin-6 levels with joint involvement and thrombocytosis in systemic juvenile rheumatoid arthritis. Arthritis Rheum. 34:1158-1163.

6. Lepore, L., M. Pennesi, S. Saletta, S. Perticarari, G. Presani, and M. Prodan. 1994. Study of IL-2, IL-6, TNF alpha, IFN gamma and beta in the serum and synovial fluid of patients with juvenile chronic arthritis. Clin. Exp. Rheumatol. 12:561-565.

7. Mangge, H., H. Kenzian, S. Gallistl, G. Neuwirth, P. Liebmann, W. Kaulfersch, F. Beaufort, W. Muntean, and K. Schauenstein. 1995. Serum cytokines in juvenile rheumatoid arthritis. Correlation with conventional inflammation parameters and clinical subtypes. Arthritis Rheum. 38:211-220.

8. De Benedetti, F., P. Pignatti, M. Massa, P. Sartirana, A. Ravelli, and A. Martini. 1995. Circulating levels of interleukin 1 beta and of interleukin 1 receptor antagonist in systemic juvenile chronic arthritis. Clin. Exp. Rheumatol. 13: 779-784.

9. Rooney, M., J. David, J. Symons, F. Di Giovine, H. Varsani, and P. Woo. 1995. Inflammatory cytokine responses in juvenile chronic arthritis. Br. J. Rheumatol. 34:454-460.

10. Prieur, A.M., P. Roux Lombard, and J.M. Dayer. 1996. Dynamics of fever and the cytokine network in systemic juvenile arthritis. Rev. Rhum. Engl. Ed. 63:163-170.

11. Tilg, H., E. Trehu, M.B. Atkins, C.A. Dinarello, and J.W. Mier. 1994. Interleukin-6 (IL-6) as an anti-inflammatory cytokine: induction of circulating IL-1 receptor antagonist and soluble tumor necrosis factor receptor p55. Blood. 83:113-118.

12. Jordan, M., I.G. Otterness, R. Ng, A. Gessner, M. Rollinghoff, and H.U. Beuscher. 1995. Neutralization of endogenous IL-6 suppresses induction of IL-1 receptor antagonist. J. Immunol. 154:4081-4090. 
13. Yoshizaki, K., T. Matsuda, N. Nishimoto, T. Kuritani, L. Taeho, K. Aozasa, T. Nakahata, H. Kawai, H. Tagoh, T. Komori, et al. 1989. Pathological significance of interleukin-6 (IL-6/BSF-2) in Castleman's Disease. Blood. 74: 1360-1367.

14. Dao, D.D., J.R. Sawyer, J. Epstein, R.G. Hoover, B. Barlogie, and G. Tricot. 1994. Deletion of the retinoblastoma gene in multiple myeloma. Leukemia. 8:1280-1284.

15. Helle, M., J. Brakenhoff, E. DeGroot, and L. Aarden. 1988. Interleukin-6 is involved in interleukin-1-induced activities. Eur. J. Immunol. 18:957-959.

16. Mule, J.J., S.G. Marcus, J.C. Yang, J.S. Weber, and S.A. Rosenberg. 1992. Clinical application of IL-6 in cancer therapy. Res. Immunol. 143:777-779.

17. Elliott, M.J., R.N. Maini, and M. Feldmann. 1995. Treatment of rheumatoid arthritis with chimeric monoclonal antibodies to tumour necrosis alpha. Arthritis Rheum. 36:1681-1690.

18. Elliott, M.J., P. Woo, P. Charles, A. Long Fox, J.N. Woody, and R.N. Maini. 1997. Suppression of fever and the acute phase response in a patient with juvenile chronic arthritis treated with monoclonal antibody to tumour necrosis factor-alpha (cA2). Br. J. Rheum. 36:589-593.

19. Wilson, A.G., J.A. Symons, T.L. McDowell, H.O. McDevitt, and G.W. Duff. 1997. Effects of a polymorphism in the human tumor necrosis factor alpha promoter on transcriptional activation. Proc. Natl. Acad. Sci. USA. 94:31953199.

20. Angotti, E., E. Mele, F. Costanzo, and E.V. Avvedimento. 1994. A polymorphism $(\mathrm{G} \rightarrow \mathrm{A}$ transition $)$ in the -78 position of the apolipoprotein A-I promoter increases transcription efficiency. J. Biol. Chem. 269:17371-17374.

21. Danis, V.A., M. Millington, V.J. Hyland, and D. Grennan. 1995. Cytokine production by normal human monocytes: inter-subject variation and relationship to an IL-1 receptor antagonist (IL-1Ra) gene polymorphism. Clin. Exp. Rheumatol. 99:303-310.

22. McDowell, T.L., J.A. Symons, R. Ploski, O. Forre, and G.W. Duff. 1995. A genetic association between juvenile rheumatoid arthritis and a novel interleukin-1 alpha polymorphism. Arthritis Rheum. 38:221-228.

23. Donn, R., A. Farham, J. Barrett, W. Thomson, J. Worthington, and W. Ollier. 1998. IL1A is not associated with UK oligoarticular JCA. Br. J. Rheum. 37(Suppl. 1):38.

24. McGuire, W., A.V. Hill, C.E. Allsopp, B.M. Greenwood, and D. Kwiatkowski. 1994. Variation in the TNF-alpha promoter region associated with susceptibility to cerebral malaria. Nature. 371:508-510.

25. Cabrera, M., M.A. Shaw, C. Sharples, H. Williams, M. Castes, J. Convit, and J.M. Blackwell. 1995. Polymorphism in tumor necrosis factor genes associated with mucocutaneous leishmaniasis. J. Exp. Med. 182:1259-1264.

26. Roy, S., W. McGuire, C. Mascie-Taylor, B. Saha, S. Hazra, A. Hill, and D. Kwiatkowski. 1997. Tumor necrosis factor promoter polymorphism and susceptibility to lepromatous leprosy. J. Infect. Dis. 176:530-532.

27. Kunkel, L.M., K.D. Smith, S.H. Boyer, D.S. Borgaonkar, S.S. Wachtel, O.J. Miller, W.R. Breg, H.W. Jones, Jr., and J.M. Rary. 1977. Analysis of human Y-chromosome-specific reiterated DNA in chromosome variants. Proc. Natl. Acad. Sci. USA. 74:1245-1249.

28. Gould, M., S. Mohamed-Ali, S. Goubet, J. Yudkin, and A. Haines. 1993. Microalbuminuria: associations with height and sex in non-diabetic subjects. BMJ. 306:240-242

29. Yudkin, J.S., C. Andres, V. Mohamed-Ali, M. Gould, A. Panahloo, A. P. Haines, S. Humphries, and P. Talmud. 1997. The angiotensin-converting enzyme gene and the angiotensin II type I receptor gene as candidate genes for microalbuminuria. A study in nondiabetic and non-insulin-dependent diabetic subjects. Arterioscler. Thromb. Vasc. Biol. 17:2188-2191.

30. Cruickshank, J.K., J. Cooper, J. MacDuff, and M. Burnett. 1991. Ethnic differences in fasting plasma $\mathrm{C}$-peptide and insulin in relation to glucose toler- ance and blood pressure. Lancet. 338:842-844.

31. Miller, S.A., D.D. Dykes, and H.F. Polesky. 1988. A simple salting out procedure for extracting DNA from human nucleated cells. Nucleic Acids Res. $16: 1215$

32. Orita, M., Y. Suzuki, T. Sekiya, and K. Hayashi. 1989. Rapid and sensitive detection of point mutations and DNA polymorphisms using the polymerase chain reaction. Genomics. 5:874-879.

33. Gudnason, V., Y.T. Mak, J. Betteridge, S.N. McCarthy, and S. Humphries. 1993. Use of the single-strand conformational polymorphism method to detect recurrent and novel polymorphisms in the low-density lipoprotein receptor gene in patients with familial hypercholesterolaemia: detection of a novel mutation Asp200 $\rightarrow$ TGly. Clin. Investig. 71:331-337.

34. Day, I.N., and S.E. Humphries. 1994. Electrophoresis for genotyping: microtiter array diagonal gel electrophoresis on horizontal polyacrylamide gels, hydrolink, or agarose. Anal. Biochem. 222:389-395.

35. Graham, F., and A. van der Eb. 1973. A new technique for the assay of infectivity of human adenovirus 5 DNA. Virology. 52:456-467.

36. Mohamed-Ali, V., S. Goodrick, A. Rawesh, J. Mile, D. Katz, J. Yudkin, and S. Coppack. 1997. Human subcutaneous adipose tissue releases IL6 but not TNF-alpha in vivo. J. Clin. Endocrinol. Metab. 82:4196-4200.

37. Yasukawa, K, T. Hirano, Y. Watanabe, K. Muratani, T. Matsuda, S. Nakai, and T. Kishimoto. 1987. Structure and expression of human B cell stimulatory factor-2 (BSF-2/IL-6) gene. EMBO J. 6:2939-2945.

38. Hollon, T., and F.K. Yoshimura. 1989. Variation in enzymatic transient gene expression assays. Anal. Biochem. 182:411-418.

39. Bowcock, A.M., J.R. Kidd, G.M. Lathrop, L. Daneshvar, L.T. May, A. Ray, P.B. Sehgal, K.K. Kidd, and L.L. Cavalli Sforza. 1988. The human "interferon-beta 2 /hepatocyte stimulating factor/interleukin-6" gene: DNA polymorphism studies and localization to chromosome 7p21. Genomics. 3:8-16.

40. Bowcock, A.M., A. Ray, H. Erlich, and P.B. Sehgal. 1989. Rapid detection and sequencing of alleles in the $3^{\prime}$ flanking region of the interleukin- 6 gene. Nucleic Acids Res. 17:6855-6864.

41. Fugger, L., N. Morling, K. Bendtzen, L. Ryder, V. Andersen, C. Heilman, F. Karup Pedersen, J. Friis, P. Halbert, and A. Svejgaard. 1989. IL-6 gene polymorphism in rheumatoid arthritis, pauciarticular juvenile rheumatoid arthritis, systemic lupus erythematosus, and in healthy Danes. J. Immunogenet. 16:461-465.

42. Linker-Israeli, M., D.J. Wallace, J.L. Prehn, R. Nand, L. Li, and J.R. Klinenberg. 1996. A greater variability in the $3^{\prime}$ flanking region of the IL-6 gene in patients with systemic lupus erythematosus (SLE). Autoimmunity. 23:199-209.

43. Murray, R., F. McGuigan, S. Grant, D. Reid, and S. Ralston. 1997. Polymorphisms of the interleukin-6 gene are associated with bone mineral density. Bone. 21:89-92.

44. Ray, A., K.S. LaForge, and P.B. Sehgal. 1990. On the mechanism for efficient repression of the interleukin-6 promoter by glucocorticoids: enhancer, TATA box, and RNA start site (Inr motif) occlusion. Mol. Cell. Biol. 10:57365746.

45. Liu, Y., H.U. Bernard, and D. Apt. 1997. NFI-B3, a novel transcriptional repressor of the nuclear factor I family, is generated by alternative RNA processing. J. Biol. Chem. 272:10739-10745.

46. Rein, T., R. Forster, A. Krause, E.L. Winnacker, and H. Zorbas. 1995 Organization of the alpha-globin promoter and possible role of nuclear factor in an alpha-globin-inducible and a noninducible cell line. J. Biol. Chem. 270: 19643-19650.

47. Murray, K., P. Donnelly, M. Passo, E. Giannini, and D. Glass. 1997. Windows of effect of disease associated HLA alleles in juvenile rheumatoid arthritis (Abstract). Arthritis Rheum. 40:S241. 